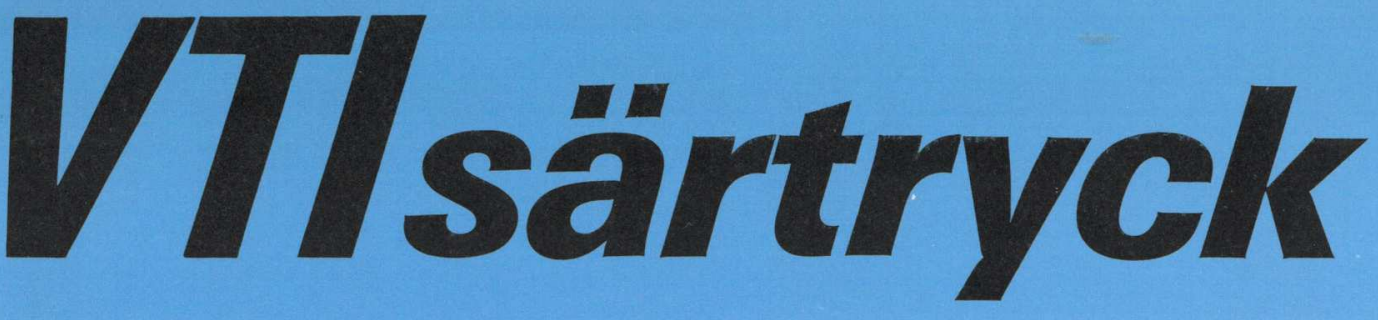

A review of the traffic safety situtation in Sweden with regard to different strategies and methods of evaluating traffic safety measures

Göran Nilsson

Reprint from Journal of Occupational Accidents, 6 (1984) 35-47 


\title{
A REVIEW OF THE TRAFFIC SAFETY SITUATION IN SWEDEN WITH REGARD TO DIFFERENT STRATEGIES AND METHODS OF EVALUATING TRAFFIC SAFETY MEASURES
}

\author{
GÖRAN NILSSON \\ Swedish Road and Traffic Research Institute (VTI), S-58101 Linköping (Sweden)
}

\begin{abstract}
Nilsson, G., 1984. A review of the traffic safety situation in Sweden with regard to different strategies and methods of evaluating traffic safety measures. Journal of Occupational Accidents, 6: 35-47.

In industrialized countries road traffic accidents cause the majority of accidental deaths. The experience from accident and casualty investigations and studies of the effect of traffic safety countermeasures can to some extent be of great value in research on occupational accidents.

This paper illustrates problems connected with the evaluation of the effects of countermeasures, problems with accident and casualty statistics, examples from investigations and of the evaluation process in order to describe the benefit of investments to increase road traffic safety in relation to traffic safety strategies in Sweden.
\end{abstract}

\section{BACKGROUND}

Experience from traffic safety research may, in many cases, be of great value for the development of occupational accident research. In literature which describes risk concepts and risk analysis, examples are often taken from road traffic in order to explain in simple terms the concept of risk. These examples more often form an expression of the author's own view of traffic than a scientifically based evaluation.

In reality, road traffic is at least as complicated as any other situation where man constitutes a meaningful part of a system. If road traffic were under the administration of a single employer and road users were regarded as employees, this area of activity, if regarded as an occupational activity, would be the first to take action due to accidents and casualties. However, since the greater part of the road transport sector has developed into an individual activity and is regarded as such, it is the road user who has to bear the larger part of the responsibility for the negative consequences together with the police and hospital services.

As in many other situations the negative results of road traffic in the form of accidents and casualties can be regarded as a lottery. We know with con- 
siderable certainty how many road users are killed or injured annualiy but we cannot predict the time, location or consequences of each accident.

We are forced to describe traffic safety for groups of road users, parts of the population or sections of the road and street network before we adopt a plan of action which in general is suited to the corresponding structure.

Through various channels for recording accidents and casualties - the police, hospitals and insurance companies - it is possible to follow trends in the number and type of accidents from one period to another in various environments.

However, these sources produce distorted pictures of the traffic safety situation - no authority has the responsibility for reporting the correct level or providing a representative picture of the traffic safety problem. The majority of decisions are based on the number and severity of accidents which have already occurred. Risk assessments are beginning to draw attention but are most often based on historical knowledge.

\section{ACCIDENT TRENDS, COUNTERMEASURES AND RISK CONDITIONS}

IN ROAD TRAFFIC

The rapidly increasing number of accidents during the 1950s was seen as a considerable social problem and was met with increased action by society in the form of investment in roads and streets, primarily to cope with the expansion of road traffic.

During the 1960s traffic regulation was given priority in the hope of limiting the continued increase in the number of accidents and casualties. The result was that traffic regulations - in the first instance, speed restrictions reduced the consequences of accidents to a greater extent than the actual number of accidents. During the 1970s this led to the political possibility of action to reduce the consequences of accidents, which resulted in legislation on the use of seat belts and crash helmets.

After the Second World War, the number of accidents and casualties corresponded fully to the increase in car traffic until the middle of the 1950s. During the 1960s, the increase in accidents was on average about 5\% units lower annually than the increase in car traffic due to the positive effect of different countermeasures.

The 1960s were characterised by over-use of cars and excessive travel at high speeds. The change to right-hand traffic in September 1967 probably meant a longterm positive effect on traffic safety - drivers and other road users started a process of re-education and speed limits were introduced throughout the whole road network, which contributed to reducing travel at high speeds.

Corresponding patterns are found in most industrialized countries but, for some reason, the traffic safety situation in Sweden has never become a "catastrophe", as it has, for example, in Japan, France or Finland. The explanation may lie in the conditions accompanying the change to right-hand 


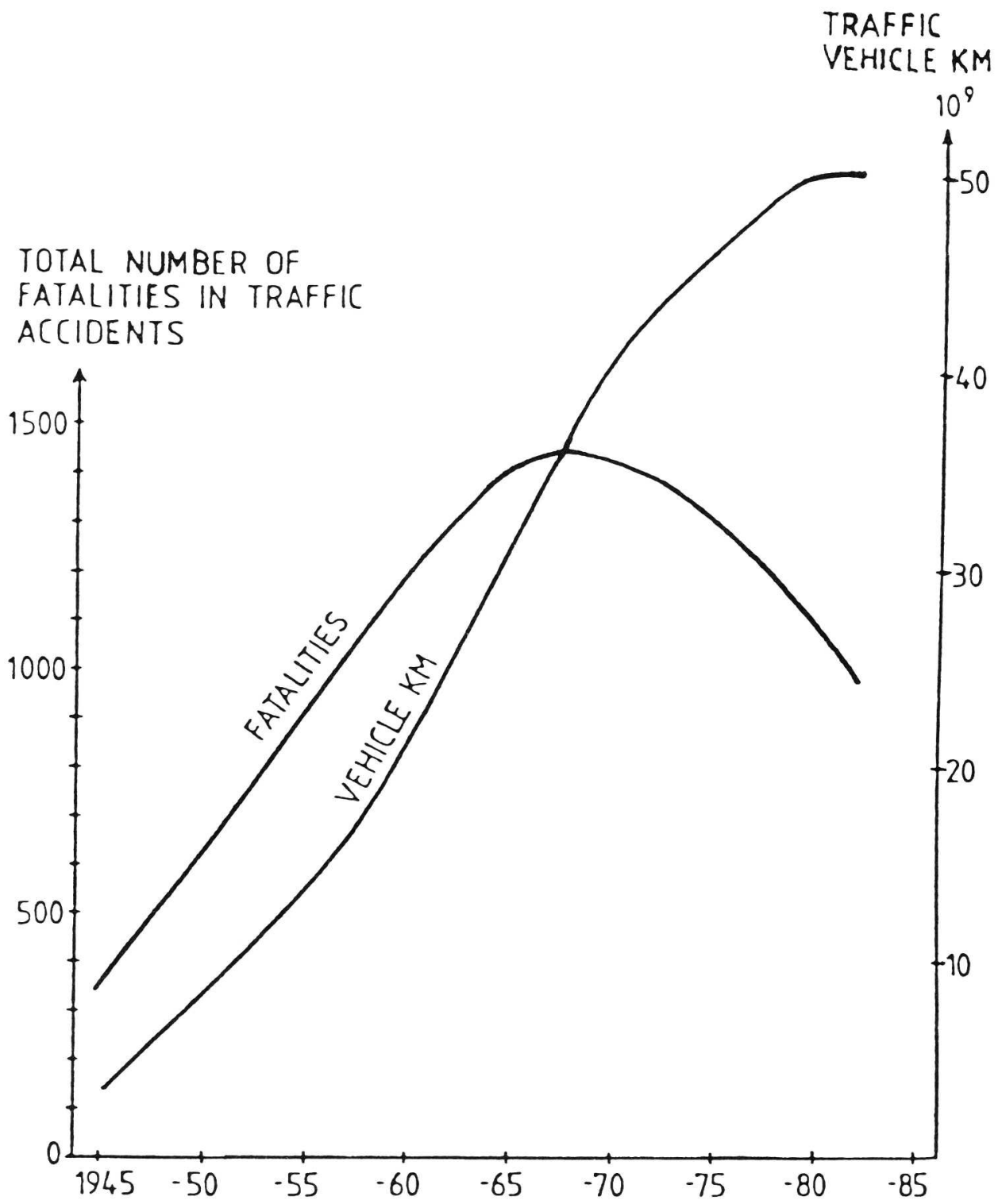

Fig. 1. Number of fatalities and vehicle-km in Sweden, 1945-1982.

traffic and roadbuilding policy during the 1960s and the years after the change. It is worth noting here that the planning of housing estates since 1965 has also taken full account of traffic safety requirements.

On the basis of information on the number of casualties in accidents reported to the police and information from travel habit surveys, it has been possible to quantify the risks to various road user categories on a national level (Thulin, 1981).

In Fig. 2, the number of casualties (including those killed) is related to the number of person-kilometres for various road user categories. The figure shows that high risks are associated with small degrees of exposure and low risks with high degrees of exposure, expressed in person-kilometres.

In Fig. 3, the number of casualties is related to the number of hours in traffic for various road-user categories. The difference in travel speeds between different road-user categories results in increased risks for motor 
NUMBER OF KILLED AND INJURED
PERSONS PER MILLION PERSONKM

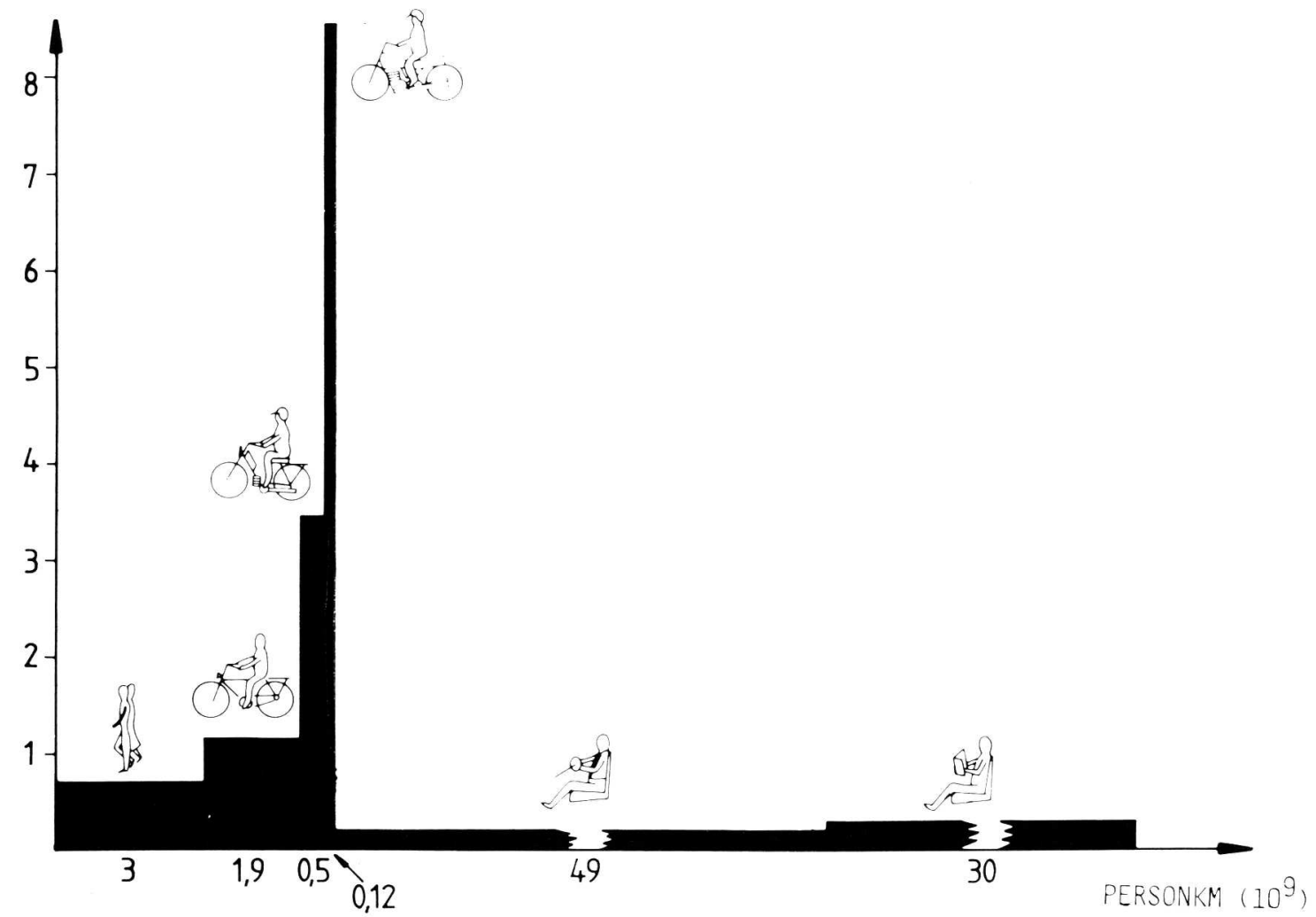

Fig. 2. Number of killed and injured people per million person-km for different road user groups.

NUMBER OF KILLED AND INJURED

PERSONS PER MILLION HOURS

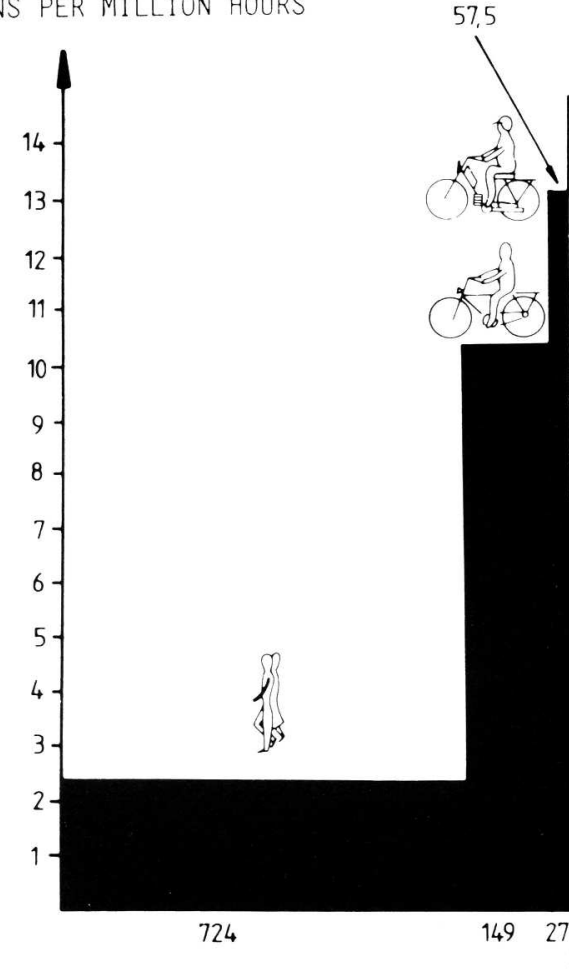

325
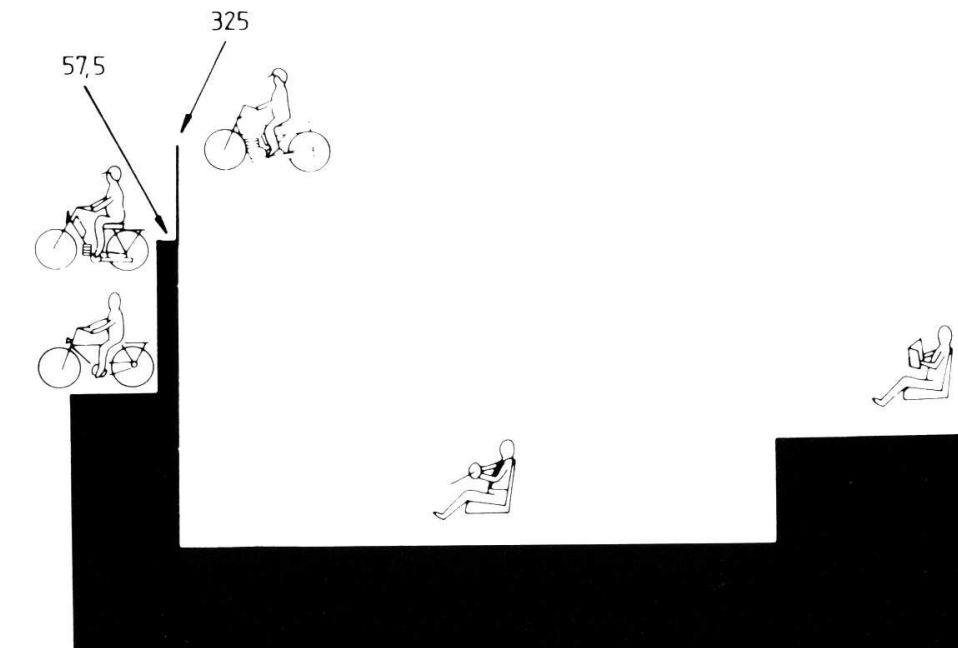
vehicles, especially for car drivers. Note that the areas shown are the product of risk and exposure, which is the same as the number of casualties.

In Fig. 4, time in traffic has been replaced by the number of trips without changing the internal order of the risk levels. The explanation for this is that the average travelling time per trip regardless of mode, is relatively constant (20 min.).

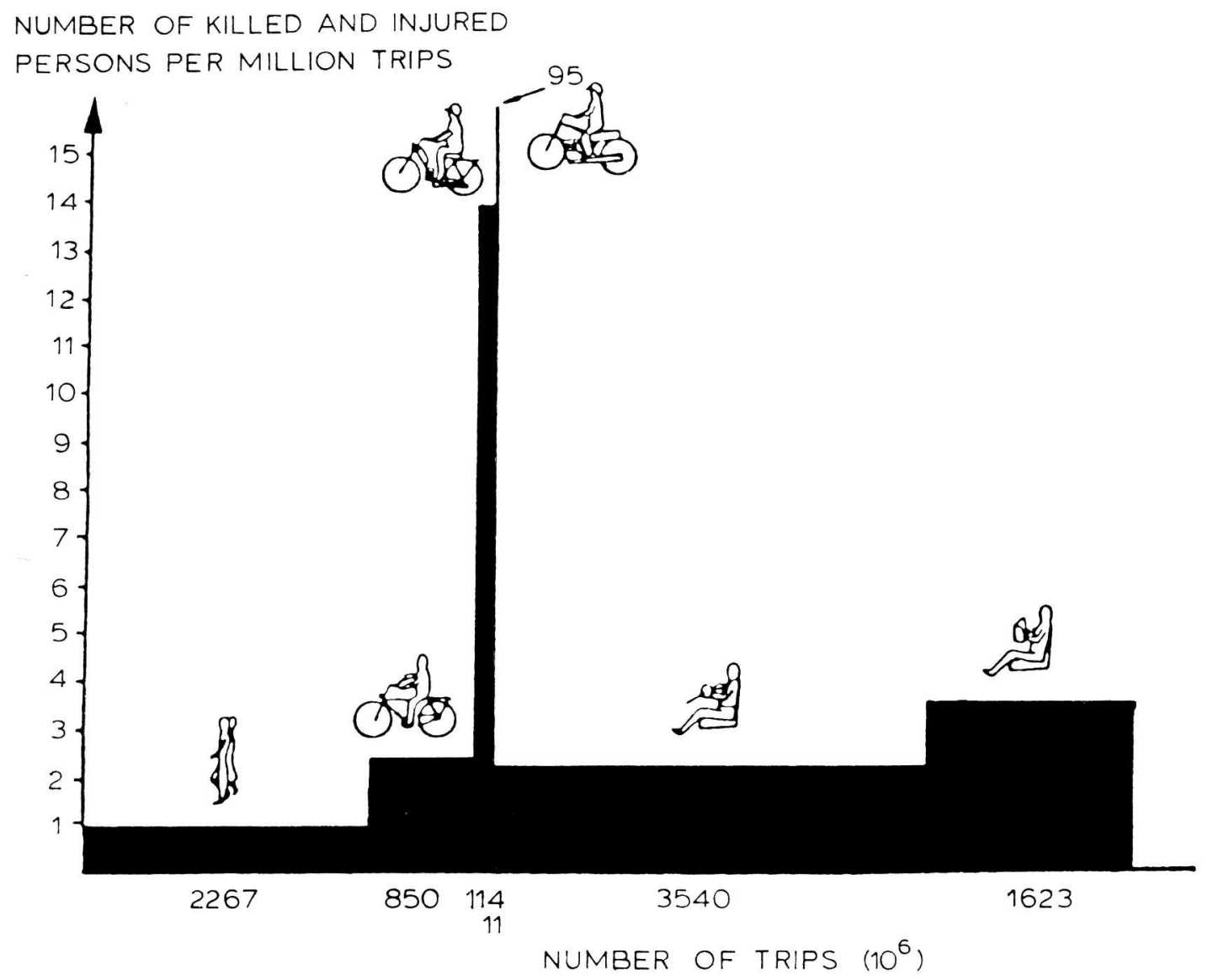

Fig. 4. Number of killed and injured persons per million trips for different road user groups.

\section{ACCIDENT AND CASUALTY STATISTICS}

Traffic safety descriptions based on reported accidents represent about $25 \%$ of all traffic casualties. The statistics are, however, almost comprehensive in the case of those killed or very seriously injured.

If we also include single accidents with bicycles and mopeds we find another $25 \%$ of the casualties. The majority of these injuries are recorded only by hospitals.

The remaining $50 \%$ of all traffic casualties consists of pedestrians who for some reason are injured when walking along roads or streets, hurrying to a bus, stumbling or falling or being injured when travelling by bus or tram.

The official traffic casualty statistics are still oriented towards describing accidents involving motor vehicles. This means that we receive a distorted 
picture of, for example, the need for hospital resources on the basis of police information, partly because of the fact that the majority of those killed do not need hospital treatment, while a large part of society's resources are required in order to care for cyclists, moped riders and pedestrians injured in single accidents not reported to the police.

Figure 5 shows a comparison between the official statistics for the severely injured and the corresponding information from hospitals (Nilsson and Thulin, 1982). Hospitals record a traffic safety problem which is twice as large as that recorded by the police and, in certain cases, is even larger in those age groups which use bicycles or walk more than other age groups.

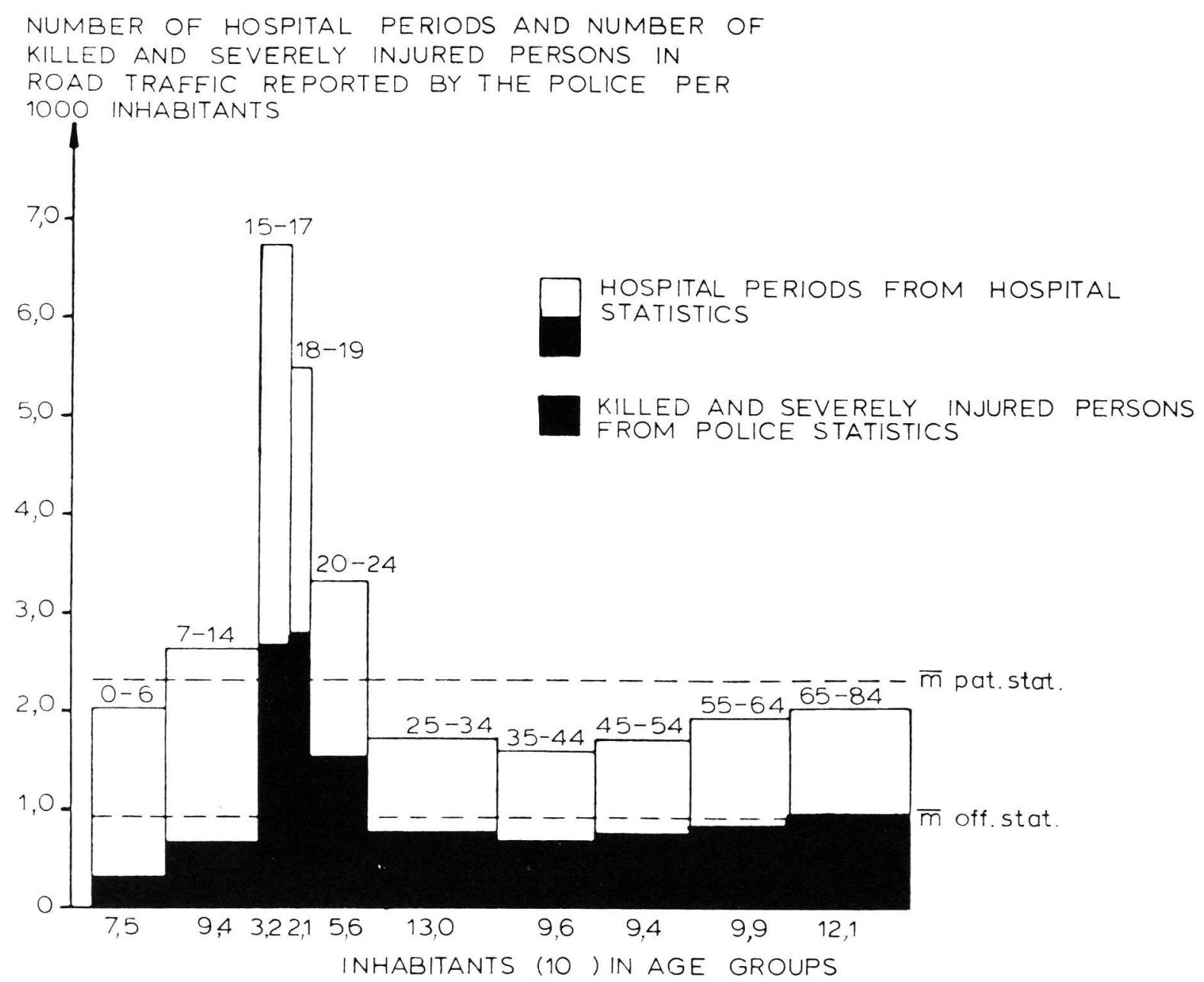

Fig. 5. Number of hospital periods per 1,000 inhabitants for people injured in road traffic, 1977. Number of people killed or severely injured in police-reported accidents per 1,000 inhabitants, 1977.

THE TRAFFIC SAFETY SITUATION AND THE EFFECTS OF DIFFERENT COUNTERMEASURES

Each countermeasure or change in traffic may alter the traffic safety situation in different ways. In principle, three different effects can be distinguished and recorded (Nilsson, 1981):

- Change in the exposure to accidents or personal injuries. 
- Change in the risk of accidents or personal injuries.

- Change in the consequences of accidents or personal injuries.

This can be illustrated in a three-dimensional figure as in Fig. 6 .

If we introduce a countermeasure this may influence one, two or all of the above effects. One example is that of speed limits which restrict exposure, risks and consequences. Increased fuel prices may influence exposure, better road standards may reduce risks and wider use of seat belts may reduce the consequences of accidents. This can be illustrated by altering the volume in Fig. 7 which is a direct measure of the number of traffic casualties.

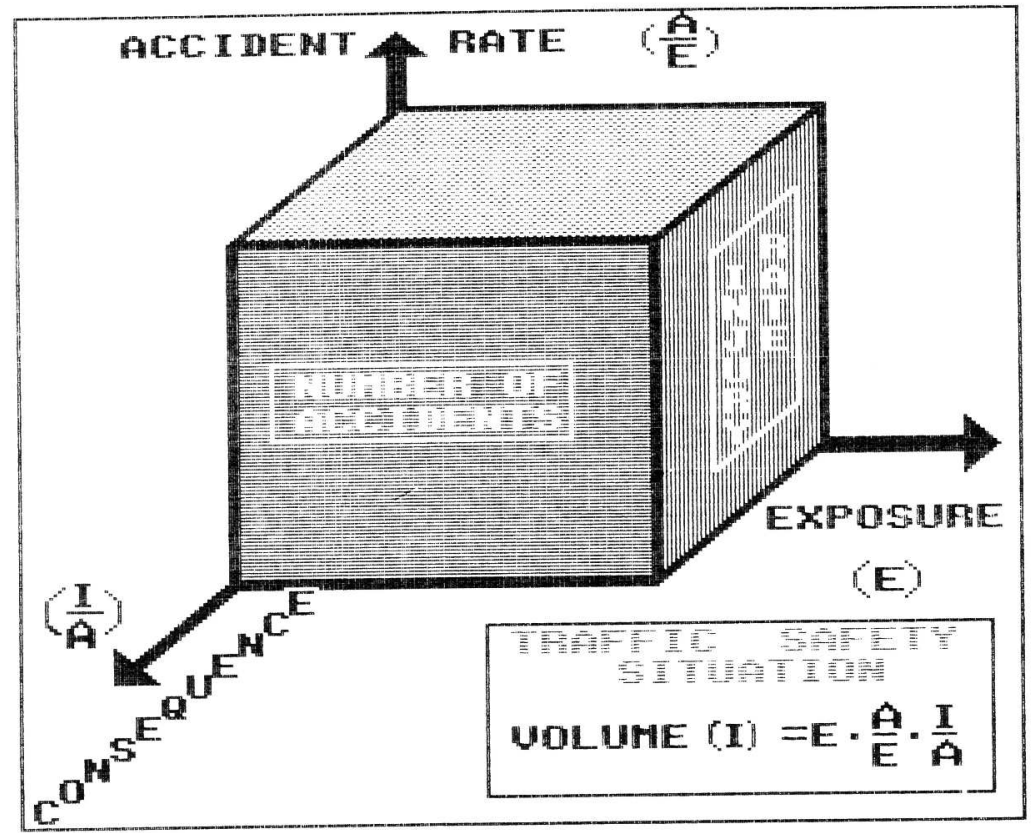

Fig. 6. Description of a traffic safety situation in terms of accident rate, accident consequences, exposure, number of accidents and injury rate.

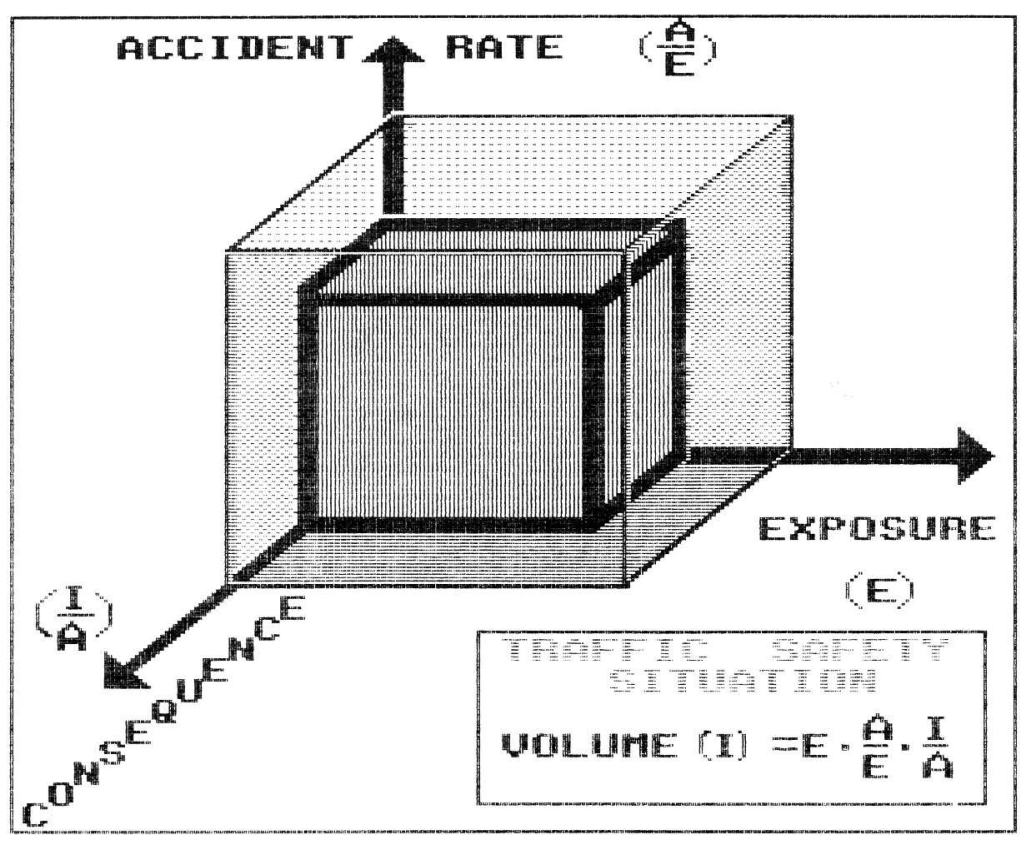

Fig. 7. The effect on the traffic safety situation if accident rate, accident consequence and exposure are reduced. 
Table 1 surveys countermeasures and expected effects related to road environment, vehicles and road users, through a two-dimensional classification of road safety measures.

One example of a countermeasure for reducing exposure to accidents or the number of casualties is the separation of pedestrians from motor traffic by pedestrian tunnels or signals. A problem occurring here is that risks increase noticeably for the group of pedestrians who do not use the tunnels or who cross against a red light. If this group increases and becomes a majority, the difference in risk between crossing against a red light and crossing with a green light will decrease. However, this does not mean to say that it is safer to cross against a red light, but the expected effect of the countermeasure will be greatly reduced.

TABLE 1

Two-dimensional classification of road safety measures

\begin{tabular}{|c|c|c|c|}
\hline $\begin{array}{l}\text { Contributing factors } \\
\text { affected by the } \\
\text { measure } \\
\text { Safe- } \\
\text { ty } \\
\text { character- } \\
\text { istic changed }\end{array}$ & Road user & Vehicle & Road/street \\
\hline Exposure & $\begin{array}{l}\text { Separation of different } \\
\text { road user categories. } \\
\text { Change in the number } \\
\text { of trips. }\end{array}$ & $\begin{array}{l}\text { Change of vehicle } \\
\text { mileage. } \\
\text { Regulation for } \\
\text { vehicle traffic. }\end{array}$ & $\begin{array}{l}\text { Regional planning } \\
\text { of traffic control. } \\
\text { Road improve- } \\
\text { ments reducing } \\
\text { travel distances. }\end{array}$ \\
\hline Risk & $\begin{array}{l}\text { Improvement of educa- } \\
\text { cation, information and } \\
\text { road user behaviour in } \\
\text { relation to traffic } \\
\text { rules. }\end{array}$ & $\begin{array}{l}\text { Crash avoidance } \\
\text { measures: Vehicle } \\
\text { speed regulations. } \\
\text { Vehicle equipment } \\
\text { (studded tires, } \\
\text { running lights in } \\
\text { daytime, etc.). }\end{array}$ & $\begin{array}{l}\text { Improvements on } \\
\text { roads, streets or } \\
\text { traffic network. } \\
\text { Speed regulation. } \\
\text { Road/street } \\
\text { maintenance. }\end{array}$ \\
\hline Accident consequence & $\begin{array}{l}\text { Individual protection } \\
\text { equipment (seat belts, } \\
\text { helmets). } \\
\text { First aid education. }\end{array}$ & $\begin{array}{l}\text { Improved crash } \\
\text { tolerance. } \\
\text { Vehicle speed } \\
\text { regulation. }\end{array}$ & $\begin{array}{l}\text { "Soft" road side } \\
\text { design. } \\
\text { Alarm telephones. }\end{array}$ \\
\hline
\end{tabular}

The same problem appears when road standards are improved. There is, for example, no difference in accident risk for single accidents on motorways and on normal two-lane roads due to the higher speeds on motorways, or other factors. Since traffic in different directions on motorways is separated the risk of collisions is reduced. However, in those cases where a vehicle 
crosses the central reservation or travels in the wrong direction by mistake the consequences are often catastrophic because of the high speeds.

Apart from speed restrictions, countermeasures to reduce risks include other types of traffic regulation, road environment, vehicle-oriented measures and information and education. Vehicle-oriented measures may relate to brakes, tyres and lighting. A concrete example is that of vehicle lighting under daylight conditions ("running lights") and reflectors on bicycles and pedestrians.

Measures such as road markings and reflective posts along the road do not, in many cases, provide the expected effect since speeds increase. This means that an expected decrease in the accident risk is reduced or does not occur at all, at the same time as the consequences of accidents increase.

Action to reduce the consequences of accidents is not yet complete. Energy-absorbing modifications to various parts of vehicles have shown positive developments. Seat belts are not yet used by all occupants, especially those who perhaps would gain the most from using them, for example young drivers and passengers during nighttime. Pedestrians who are run over often receive unnecessary injuries as a result of the design of vehicles. It is precisely in quantifying how consequences are changed by various measures that most research is needed. This must be coordinated with the information available from hospitals.

\section{TRAFFIC SAFETY RESEARCH}

When investigating the effects of countermeasures there are probably few areas which have attracted as much interest as road traffic, at the same time as research resources have been limited.

In spite of the relatively comprehensive investigations and the fact that research has largely been done on the basis of available information not always suited to the problems studied, a considerable amount of knowledge has been gained regarding the background to traffic accidents. This is however often confused with ideas which have no connection with reality and with results which reflect rather an unsatisfactory investigation methodology rather than the effect on traffic safety. These "false truths" play a part which is not insignificant when decisions are made in the road transport sector.

There is, therefore, a body of opinion which has not wholly accepted the speed restriction system and is above all an opponent to further reductions in speed limits on roads where most accidents occur. Arguments that one becomes tired when driving at $90 \mathrm{~km} / \mathrm{h}$ or that it is difficult to overtake where speed limits are in force are still heard occasionally.

Perhaps the greatest problem is that the effect of many road and traffic measures and of information and education activities is overestimated by the use of unsuitable investigation methods or by the absence of possibilities of measuring any effects. 
Investigations in the form of statistical experiments - objects selected at random for treatment - to quantify the effects of measures are not accepted although practical experiments involving such measures are made without either checks being made or the desire to obtain information on the real effect of the measures.

The whole traffic system can be regarded as a gigantic experiment - new vehicles and new traffic regulations are all too often introduced without either planning or the intention of evaluating the effects. The discovery is made too late that it would be desirable to quantify the effects, usually because an individual person's suspicion has been aroused.

This unplanned situation often results in retrospective before and after studies. However, in those cases where action has been taken because of high accident rates, which is the normal case, it is impossible to eliminate random effects from the effects of the measures - regression to the mean effect. This procedure also means that all control possibilities are eliminated and the control object used must consist of objects which differ from the test object in some essential respect.

Measures are often applied to junctions, drivers and vehicles as though they had an abnormally high number of accidents or a high accident risk. As a result of the problem of the regression to the mean, the number of accidents or the accident risk will be reduced even if no countermeasures are taken. Many lists of countermeasures often include more random effects than actual effects.

A before-and-after study of road intersections in Sweden which remained unmodified during the years 1972-1978 (Table 2), showed that a halving of the number of personal injury accidents may be expected to be due simply to regression to the mean (Brüde and Larsson, 1982). It is not unusual for effects of this order of size to be reported in before and after studies of countermeasures.

Finally, I shall give an illustrative example regarding road conditions and traffic safety in winter (Andersson, 1978). Ice and snow on the road are a TABLE 2

Regression to the mean injury accidents at intersections - Sweden (Figures in ( ) are exposure adjusted)

\begin{tabular}{llll}
\hline $\begin{array}{l}\text { Number of } \\
\text { intersections } \\
\text { ingroup }\end{array}$ & $\begin{array}{l}\text { No. of accidents per } \\
\text { intersection during } \\
\text { "before" period }\end{array}$ & $\begin{array}{l}\text { Average no. of accidents per } \\
\text { intersection during equivalent } \\
\text { "after" period }\end{array}$ & Change (\%) \\
\hline 2039 & $0(0)$ & 0.19 & Increase \\
441 & $1(0.85)$ & 0.42 & $(-51)$ \\
119 & $2(1.70)$ & 0.71 & $(-59)$ \\
24 & $3(2.56)$ & 1.33 & $(-48)$ \\
14 & $4.143(3.53)^{\mathrm{a}}$ & 1.50 & $(-57)$ \\
\hline
\end{tabular}

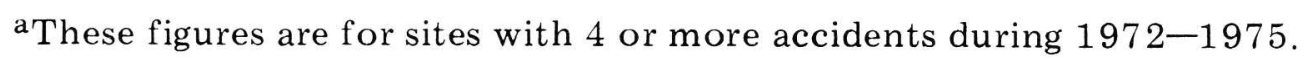


problem for all road users. The occurrence of ice and snow can be reduced by spreading salt, which is expected to bring down the number of accidents. Figure $8 \mathrm{~A}$ describes a situation where half the traffic uses roads affected by ice and snow while the other half uses roads free of ice and snow during a given period of time.

The accident rate is twice as high under conditions of ice and snow compared with roads free of ice and snow. Two thirds of the accidents occur under conditions of ice and snow.

If salt is used it is possible to eliminate half the ice and snow conditions.

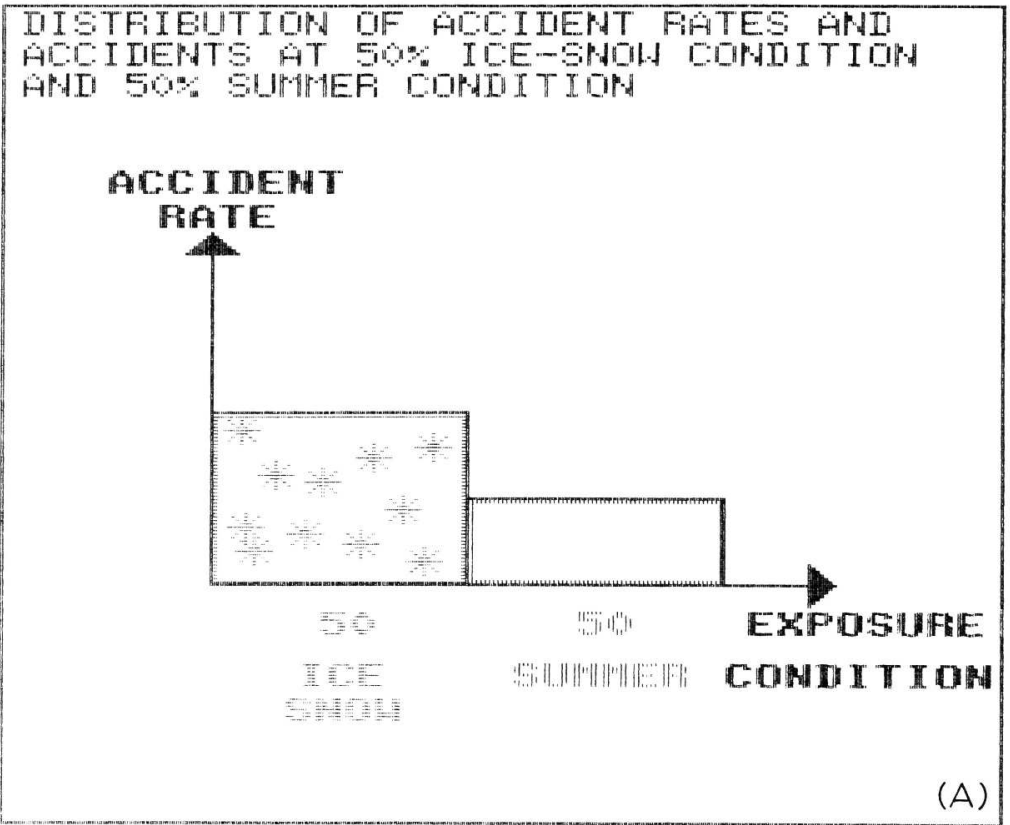

Fig. 8a.

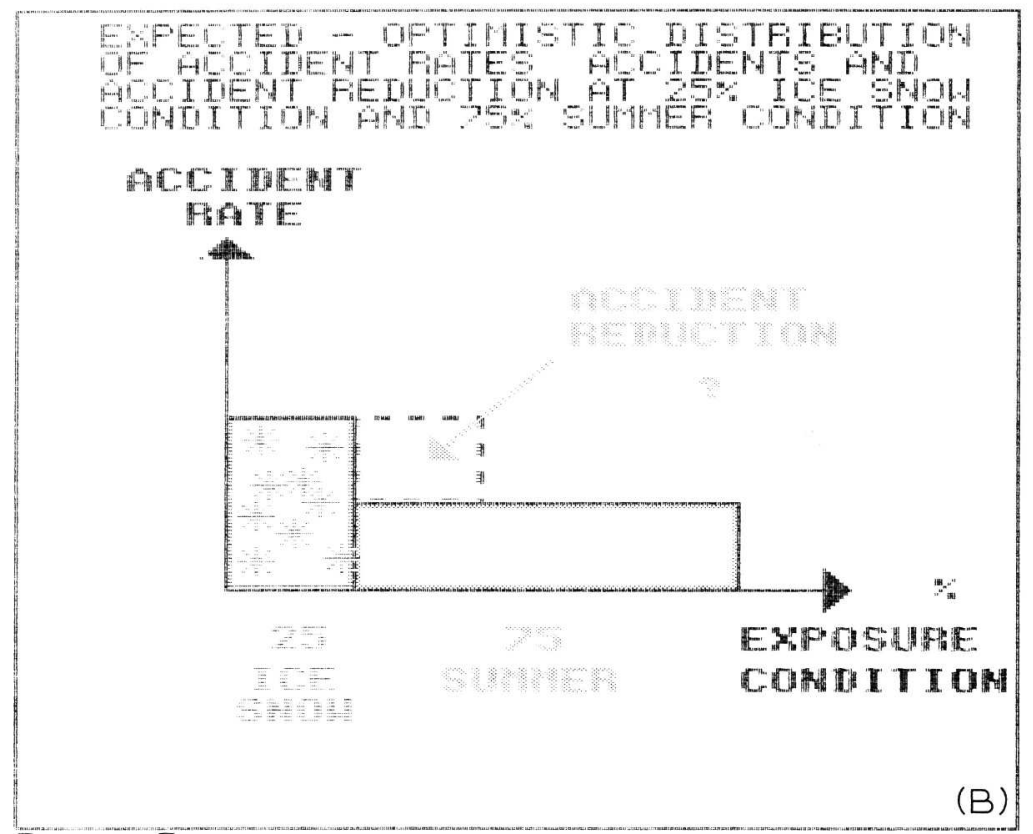

Fig. 8 b. 


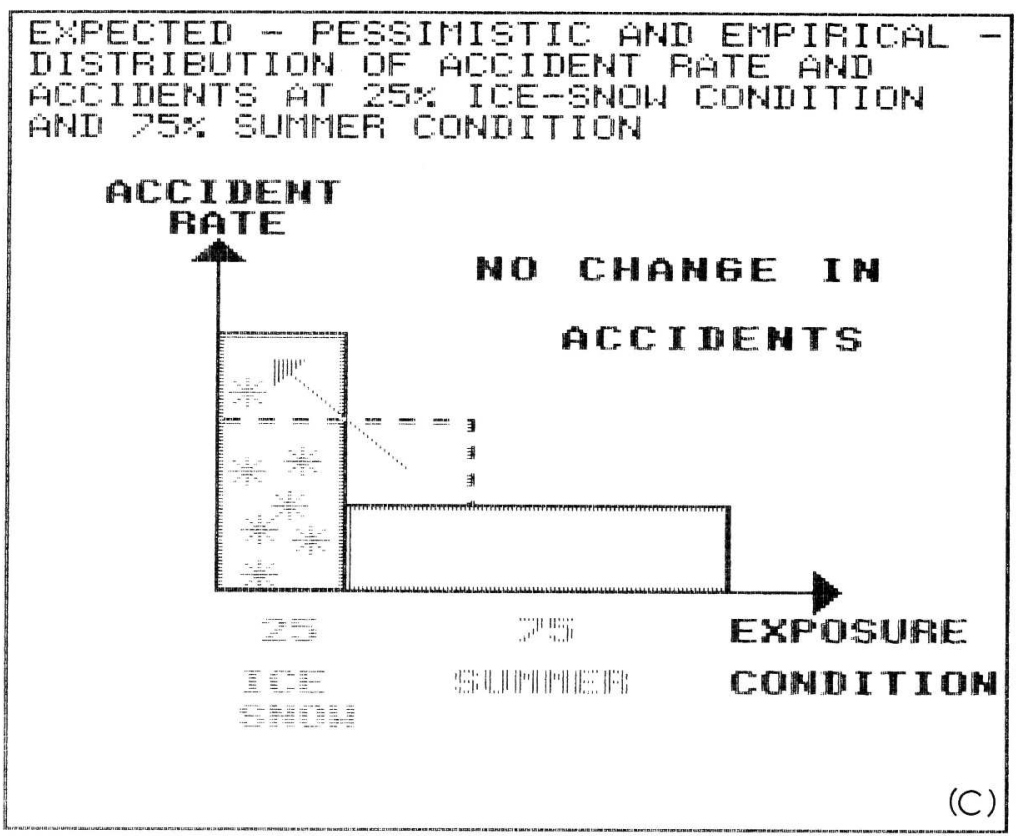

Fig. 8c.

Assuming that the accident risks are unchanged the result shown in Fig. $8 \mathrm{~B}$ is obtained.

The investigations show, however, that reality is different (Fig. 8C).

The risk has increased by 50\% under ice and snow conditions, which means that the number of accidents is unchanged. These results have led to an experiment being made with unsalted roads in Sweden, although on a modest scale. The results indicate that when the existence of ice and snow is reduced the accident rate increases on the remaining parts of the roads with ice and snow

\section{COST-BENEFIT ANALYSIS IN THE EVALUATION OF THE EFFECTS OF COUNTERMEASURES}

When undertaking cost-benefit analysis, the road transport sector forms an interesting area. Traffic planning often relates to the expected accident costs, travel time costs and vehicle costs when illuminating the benefit of a new road or road improvement. However, I will not enter here into the evaluation problems arising mainly from accident and travel time costs.

In order to demonstrate society's valuation, a figure of $\mathrm{S}$. $\mathrm{Kr} .3$ million is used for every person killed, 400,000 for every person severely injured and 150,000 for every person slightly injured. In reality this means that almost half the calculated accident costs are associated with fatalities.

The cost-benefit analysis is used both to create a priority ruling between different road projects and in conjunction with different road maintenance strategies.

Measures which alter vehicle speeds are of special interest here, since all costs can be related to speeds. They also include the present speed restriction 
systems which indirectly form the background to the relationship between accident and travel time costs.

For society as a whole the above-mentioned cost-benefit models must, however, be supplemented with other unquantified effects, such as employment, regional politics etc., which means that priority rulings are often invalidated. I believe that the latter problems coincide to a great extent with problems of research into occupational accidents and the consequences of these accidents for society.

\section{REFERENCES}

Andersson, K., 1978. Chemical de-icing of roads - effects on road accidents. Report 145, VTI, Linköping.

Brüde, U. and Larsson, J., 1982. The regression-to-mean effect-Some empirical examples concerning accidents at road junctions. Report 70, VTI, Linköping.

Nilsson, G., 1981. Traffic safety in terms of accidents, injuries, risks and consequences a multidimensional method for the description of traffic safety situations. Ninth IRF World Meeting, Road Design and Safety. Stockholm 1981.

Nilsson, G. and Thulin, H., 1982. A description of the traffic safety situation based on patient statistics from the National Welfare Board. Report 237, VTI, Linköping.

Thulin, H., 1981. Traffic risks for different age groups and modes of transport. Report 209, VTI, Linköping. 
